\title{
Komposisi Fitoplankton di Pantai Maron Semarang
}

\author{
Maria Ulfa Ramadhanty*, Suryono, Gunawan Widi Santosa \\ Departemen IImu Kelautan, Fakultas Perikanan dan IImu Kelautan, Universitas Diponegoro \\ JI. Prof.H.Soedarto S.H, Tembalang, Semarang, Jawa Tengah 50275 Indonesia \\ *Corresponding author, e-mail : mariaulfaramadhanty@gmail.com
}

\begin{abstract}
ABSTRAK: Pantai Maron merupakan kawasan pesisir di kota Semarang sebagai destinasi wisata, namun sekitarnya ditemukan beberapa aktivitas seperti reklamasi pantai, membuang sampah di laut, serta kegiatan industri yang membuang limbahnya ke dalam laut. Aktivitas tersebut berdampak pada perubahan kondisi perairan sehingga akan berpengaruh terhadap kelimpahan fitoplankton. Penelitian ini bertujuan untuk mengetahui komposisi dan sebaran fitoplankton. Metode penelitian yang digunakan adalah metode survei. Pengambilan sampel terdiri dari 3 stasiun yaitu muara, pantai dan laut. Masing-masing stasiun terdiri dari 5 titik. Hasil menunjukkan Pantai Maron Semarang ditemukan 3 kelas fitoplankton yaitu Bacillariophyceae, Dinophyceae dan Cyanophyceae yang terdiri dari 24 genera. Kelimpahan fitoplankton tertinggi ditemukan pada stasiun 3 yaitu 11549,89 dan kelimpahan terendah pada stasiun 1 yaitu 7109,30. Hasil indeks keanekaragaman ( $H^{\prime}$ ) fitoplankton di setiap stasiun berkisar antara 2,72 - 2,76 termasuk pada kategori sedang. Indeks keseragaman (E) fitoplankton di setiap stasiun antara 0,94 - 0,96 yang tergolong keanekaragaman tinggi sedangkan nilai indeks dominasi (D) fitoplankton pada setiap stasiun yaitu 0,07 yang tergolong dominasi rendah atau tidak terdapat individu jenis yang mendominasi.
\end{abstract}

Kata kunci: Kelimpahan; Fitoplankton; Pantai Maron; Semarang

\section{Composition Phytoplankton in Maron Beach Semarang}

ABSTRACT: Maron Beach there are activities from tourists and activities near the Maron Beach area such as the reclamation of the beach, disposing of trash in the sea and industrial activities whose waste disposal will enter the sea. These activities have an impact on changes in water conditions that affect the abundance of phytoplankton. This study aims to determine the composition and distribution of phytoplankton related to physical and chemical parameters at the November 2019 study site conducted in situ. Sampling consisted of 3 stations estuary, beach and sea. Each station consists of 5 points. The results showed Maron Beach Semarang found 3 classes of phytoplankton, there is Bacillariophyceae, Dinophyceae and Cyanophyceae consisting of 24 genera. The highest abundance of phytoplankton was found at station 3 namely 11549.89 and the lowest abundance at station 1 was 7109.30. The results of diversity index $(H$ ') phytoplankton at each station ranged from 2.72 to 2.76 included in the medium category. Phytoplankton uniformity index (E) at each station between $0.94-0.96$ which is classified as high diversity while the value of phytoplankton dominance index (D) at each station is 0.07 which is classified as low dominance or there is no dominating individual type.

Keywords: Abundance; Phytoplankton; Maron Beach; Semarang

\section{PENDAHULUAN}

Pantai Maron terletak di Kelurahan Tambakharjo Kota Semarang. Pantai Maron Semarang sebagai tempat rekreasi pantai dan merupakan potensi wisata yang dikembangkan (Fithor et al., 2013). Namun, perairan di kawasan Pantai Maron Semarang sangat keruh yang mengurangi nilai estetika dari Pantai Maron itu sendiri. Hal ini disebabkan karena kegiatan-kegiatan baik dari wisatawan maupun kegiatan di dekat kawasan Pantai Maron itu sendiri seperti adanya reklamasi pantai, membuang sampah di laut, kegiatan pabrik-pabrik yang berada di dekat Pantai Maron 
bahkan aktivitas rumah tangga. Dampak masuknya limbah ke dalam perairan Pantai Maron Semarang secara terus menerus akan menyebabkan perairan menjadi kelewat subur (Hypereutrophic). Menurut Simbolon (2016), Perairan yang kelewat subur akan mengalami eutrofikasi. Eutrofikasi yang ditandai dengan terjadinya peningkatan kelimpahan fitoplankton (blooming algae). Keberadan fitoplankton dapat memberikan informasi kualitas perairan. Fitoplankton adalah bioindikator kualitas perairan kualitas dan kesuburan suatu perairan.

Melihat kondisi yang ada di kawasan Pantai Maron ini, maka perlu dilakukan penelitian guna mengetahui kualitas perairan di lokasi penelitian. Tujuan dari penelitian ini untuk mengetahui komposisi fitoplankton dengan mengidentifikasi kualitas perairannya. Identifikasi kualitas perairan ini dilakukan dari beberapa objek pengamatan, diantaranya: Suhu, DO, kecerahan, $\mathrm{pH}$, salinitas, fosfat, nitrat dan amonia serta kelimpahan dan distribusi jenis fitoplankton yang terdapat di perairan Pantai Maron Semarang. Dengan mengetahui kualitas perairan di lokasi penelitian maka diharapkan masyarakat terutama wisatawan untuk dapat lebih memelihara lingkungan dengan baik agar Pantai Maron Semarang dapat dimanfaatkan secara berkelanjutan.

\section{MATERI DAN METODE}

Materi penelitian adalah air yang diambil dari lokasi penelitian yang selanjutnya dianalisis kandungan unsur hara (nitrat dan fosfat). Sedangkan parameter pendukung penelitian meliputi salinitas, $\mathrm{pH}$ (Derajat Keasaman), DO, suhu dan kecerahan dilakukan pengukuran di lapangan secara in situ. Sampel fitoplankton diambil dengan menggunakan kapal secara horizontal dengan menyaring air sebanyak 100 liter dengan menggunakan plankton net yang memiliki diameter $20 \mathrm{~cm}$ dan mesh size $37 \mu \mathrm{m}$. Hasil penyaringan kemudian diawetkan dengan formalin 4\%.

Metode yang digunakan yaitu metode survei. Teknik pengambilan sampel dilakukan dengan metode purposive sampling yaitu pemlihan sekelompok obyek berdasarkan atas ciri-ciri yang sudah ada sebelumnya (Aprilia, 2015). Lokasi pengambilan sampel terdiri dari 3 stasiun yang masing-masing stasiun memiliki 5 titik yang menyebar dari pusat muara. Stasiun kesatu (A) merupakan stasiun yang dekat dengan muara. Stasiun kedua (B) berada 150 m dari stasiun satu sedangkan stasiun ketiga (C) berada $200 \mathrm{~m}$ dari stasiun kedua (B). Teknik pengambilan sampel dilakukan berdasarkan pertimbangan yang berfokus pada tujuan tertentu. Ketiga stasiun memiliki parameter dan kandungan zat hara yang berbeda. Pengamatan jenis fitoplankton dihitung dalam wadah sedgwick rafter kemudian diamati dengan menggunakan mikroskop binokuler dengan perbesaran $10 \times 10$ yang selanjutnya di identifikasi dengan menggunakan buku identifikasi fitoplankton.

\section{HASIL DAN PEMBAHASAN}

Hasil identifikasi fitoplankton ditemukan 24 genera fitoplankton terdiri dari 3 kelas yaitu Bacillariophyceae, Dinophyceae dan Cyanophyceae. Fitoplankton terbanyak yang ditemukan adalah kelas Bacillariophyceae yaitu 17 genus, selanjutnya kelas Dinophyceae ditemukan 6 genus, sedangkan kelas Cyanophyceae adalah kelas yang paling jarang ditemukan yaitu hanya 1 genus. Pada setiap stasiun terdapat perbedaan jenis fitoplankton yang ditemukan. Jenis fitoplankton terbanyak rata-rata terdapat di stasiun 2 yaitu di Pantai. Perbandingan komposisi jenis fitoplankton di Pantai Maron Semarang dapat dilihat pada Gambar 2.

Komposisi jenis fitoplankton terbanyak didominasi oleh kelas Bacillariophyceae hal ini dikarenakan Bacillariophyceae memiliki toleransi kemampuan terhadap lingkungan dalam kondisi apapun. Distribusi dari kelas Bacillariophyceae sangat luas meliputi air laut sampai air tawar. Kondisi ini disebabkan oleh kemampuan reproduksi dari kelas Bacillariophyceae yang lebih besar dibandingkan dengan kelompok fitoplankton lainnya. Kelas Bacillariophyceae merupakan produsen primer yang melimpah di daerah permukaan yang memiliki intensitas cahaya yang cukup dan kaya akan unsur hara. Soeprobowati (2011) dalam Nurlaelatun et al. (2018) mengungkapkan bahwa kelas Bacillariophyceae mempunyai beberapa keunggulan dibandingkan dengan organisme lain, diantaranya distribusinya yang luas dengan populasi yang bervariasi, mempunyai peran penting di dalam rantai makanan, siklus hidup pendek, cepat bereproduksi, dijumpai di hampir semua substrat sehingga mampu merekam sejarah habitatnya, serta banyak dari spesiesnya yang sensitif terhadap perubahan lingkungan sehingga cepat merespon, mampu 
merefleksikan perubahan-perubahan kualitas air dalam jangka pendek maupun jangka panjang, mudah dalam pengambilan sampel, analisis dan identifikasinya.

Kelas Dinophyceae yang ditemukan di Pantai Maron Semarang terdapat 6 genus yaitu Gymnodinium, Peridinium, Protoperidinium, Prorocentrum, Ceratium dan Dinophysis. Beberapa jenis dinoflagelata atau dinophyceae dapat menyebabkan terjadinya red tide yang dapat mematikan ikan-ikan yang ada di dalamnya. Hal ini diperjelas oleh Mujib et al. (2015) bahwa pertumbuhan yang cepat dari plankton dinoflagelata diduga akan menghasilkan warna coklat atau merah perubahan wama air disebut red tides. Red tides biasanya terjadi pada air pesisir pantai dan muara. Dalam beberapa kasus, racun dapat menyebabkan kematian ikan dan keracunan manusia yang makan makanan yang terkontaminasi oleh moluska atau ikan. Dinoflagelata juga dapat menyebabkan terjadinya HABs (Harmful Algae Blooms).

Komposisi jenis fitoplankton yang jarang ditemukan adalah kelas Cyanophyceae. Kelas Cyanophyceae hanya ditemukan 1 genus yaitu Oscillatoria yang terdapat di setiap stasiun dalam jumlah yang sedikit dibandingkan kelas lainnya. Menurut Munthe et al. (2012), Cyanophyceae biasanya jarang dijumpai, tetapi kadang-kadang akan muncul tiba-tiba dalam ledakan populasi yang amat besar dan tak lama kemudian akan menghilang lagi dengan sangat cepat. Menurut Harmoko dan Sepriyaningsih (2018), kelas Cyanophyceae dapat tumbuh pada lingkungan yang toksik sehingga Cyanophyceae dapat menjadi penyeimbang perairan. Menurut penelitian Widodo (2014), di Perairan Muara Sungai Semarang didapatkan jenis fitoplankton dari kelas Cyanophyceae yang sering ditemukan pada penelitian ini adalah genus Oscillatoria.

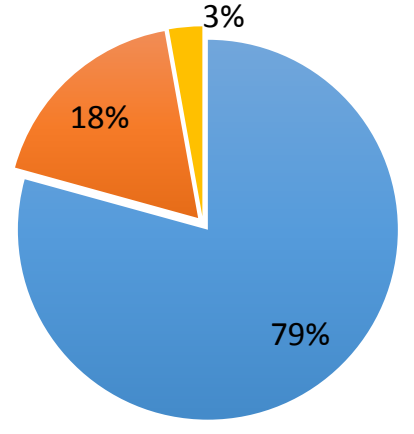

Bacillariophyta Dinophyceae $\square$ Cyanophyceae

Stasiun 1

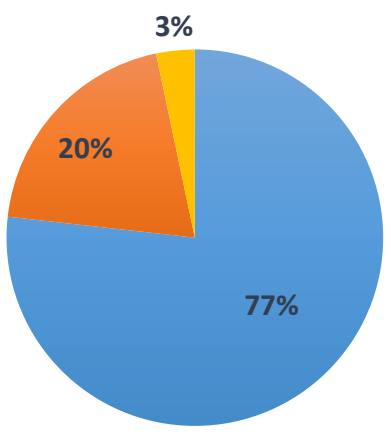

Bacillariophyta Dinophyceae $\square$ Cyanophyceae

Stasiun 2

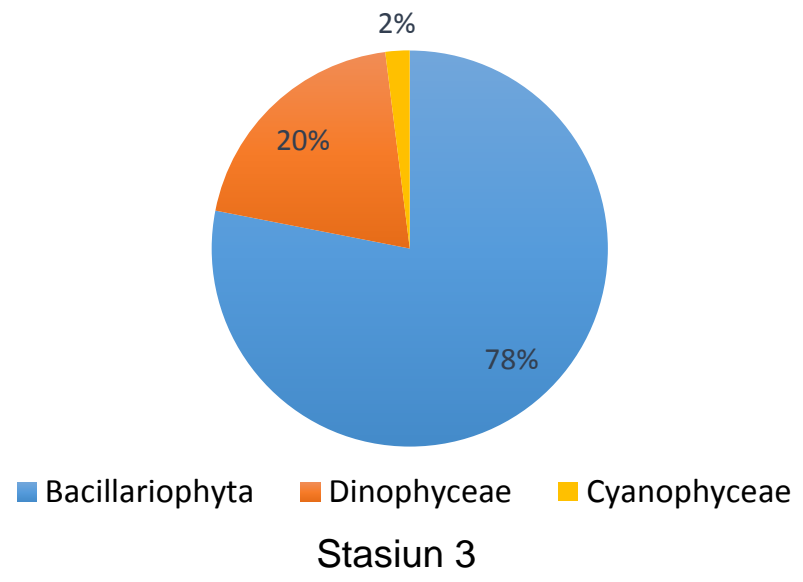

Gambar 2. Komposisi Fitoplankton di Pantai Maron Semarang 
Hasil analisis kelimpahan menunjukkan bahwa setiap stasiun memiliki kelimpahan yang berbeda. Kelimpahan tertinggi ditemukan pada stasiun 3 yaitu 11549,89 sel/L. Sedangkan kelimpahan terendah dimiliki oleh stasiun 1 yaitu 7109,30 sel/L. Pada stasiun 2 memiliki kelimpahan $8870,32 \mathrm{sel} / \mathrm{L}$. Perbandingan kelimpahan pada setiap stasiun di Pantai Maron Semarang tersaji pada Gambar 3.

Kelimpahan fitoplankton yang berperan sebagai produktivitas primer dipengaruhi oleh unsur hara seperti nitrat dan fosfat. Sumber utama zat hara fosfat dan nitrat berasal dari perairan itu sendiri yaitu melalui proses-proses penguraian dan dekomposisi ataupun dari limbah-limbah yang terbawa ke laut. Menurut Patty (2015), kadar fosfat di perairan laut yang normal berkisar antara 0,01-4 $\mu \mathrm{g}$.at/L atau setara dengan 0,00031-0,124 mg/L, sedangkan kandungan nitrat yang normal di perairan laut umumnya berkisar antara 0,01-50 $\mu \mathrm{g}$.at/L atau setara dengan 0,00014-0,7 mg/L. Pada titik 3 memiliki nilai nitrat dan fosfat yang lebih tinggi dibandingkan dengan titik lainnya yaitu nilai nitrat 0,41 dan nilai fosfat 0,099 . Hal ini menunjukkan bahwa kelimpahan yang tertinggi terdapat di laut. Menurut Paiki dan Kalor (2017), menyatakan bahwa konsentrasi nitrat yang baik untuk pertumbuhan fitoplankton berkisar antara 0,09-3,5 mg/L sedangkan fosfat yang baik untuk pertumbuhan fitoplankton yang baik dibutuhkan kandungan fosfat yang berkisar antara $0,08-1,80$ $\mathrm{mg} / \mathrm{l}$.

Kecerahan pada setiap titik berbeda, pada titik 1 atau muara memiliki kecerahan yang lebih rendah dibandingkan dengan titik 2 dan titik 3 yaitu $80,5 \mathrm{~cm}$. Sedangkan titik 3 yang berlokasi di laut memiliki kecerahan $185 \mathrm{~cm}$. Kekeruhan yang terjadi di muara disebabkan karena adanya reklamasi pantai di dekat muara, sehingga permukaan laut menjadi semakin dangkal. Selain itu, kekeruhan terjadi akibat beban masukan dari aktivitas manusia seperti limbah dan polutan yang mengalir ke muara. Menurut Irawati et al. (2013), kekeruhan yang tinggi akan mempengaruhi penetrasi cahaya ke dalam kolom perairan, sehingga akan menurunkan produktivitas primer fitoplankton di perairan. Hal ini sesuai dengan hasil yang didapat bahwa kelimpahan fitoplankton di titik 1 relatif lebih rendah dibandingkan dengan titik 2 dan 3. Semakin sedikit cahaya yang masuk akan menurunkan aktivitas fotosintesis yang berakibat menurunnya kelimpahan fitoplankton di perairan. Salinitas juga merupakan faktor pendukung dari kelimpahan fitoplankton. Titik 3 memiliki salinitas yang optimal dibandingkan dengan salinitas di titik 1 dan titik 2 yaitu $31 \%$ o. Menurut Faturohman et al. (2016), bahwa salinitas yang baik untuk pertumbuhan plankton di laut adalah 30 - 35\% sehingga di laut memiliki kelimpahan yang relatif lebih tinggi dari muara dan pantai. Hal ini diungkapkan oleh Nova dan Misbah (2012), bahwa umumnya fitoplankton tumbuh optimal pada salinitas $30-40 \%$. Pada titik 1 yang berlokasi di muara memiliki salinitas terendah dibandingkan titik lainnya yaitu $29 \%$. Sehingga pada muara terdapat kelimpahan yang lebih rendah dibandingkan titik lainnya.

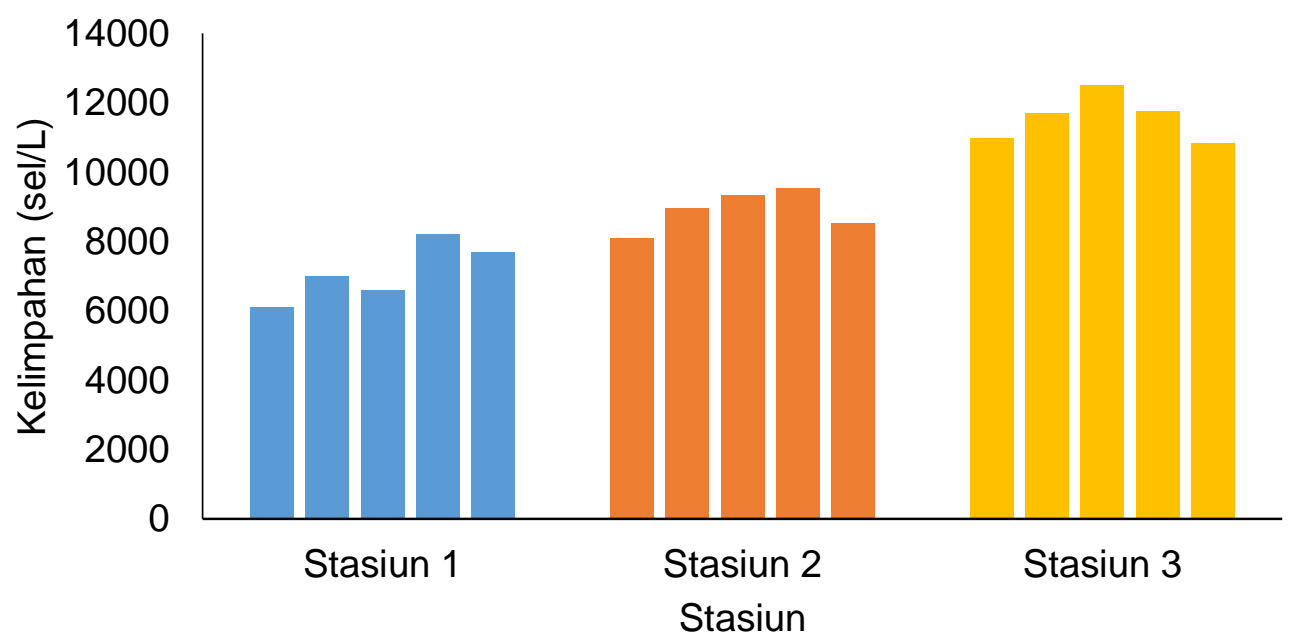

Gambar.3. Kelimpahan Fitoplankton (sel/L) di Pantai Maron Semarang 
Hasil analisis indeks keanekaragaman diperoleh hasil indeks keanekaragaman $\left(H^{\prime}\right)$ fitoplankton berkisar antara 2,72-2.76. Nilai indeks keanekaragaman $1<\mathrm{H}^{\prime}<3$ termasuk ke dalam kategori sedang sehingga nilai indeks keanekaragaman yang didapat tergolong dalam keanekaragaman sedang. Rata-rata indeks keanekaragaman tertinggi berada di stasiun 2 yaitu 2,76 . Sedangkan rata-rata indeks keanekaragaman terendah berada di stasiun 1 yaitu 2,72. Pada stasiun 3 memiliki rata-rata indeks keanekaragaman 2,74. Perbandingan indeks keanekaragaman $\left(\mathrm{H}^{\prime}\right)$ pada setiap stasiun di Pantai Maron Semarang tersaji pada Gambar 4. Menurut Hidayat et al. (2015), indeks keanekaragaman dapat dijadikan petunjuk seberapa besar tingkat pencemaran suatu perairan. Patty (2018) menambahkan, apabila nilai indeks keanekaragaman 2,0-3,0 merupakan perairan tercemar ringan. Hal ini menunjukkan bahwa perairan di Pantai Maron Semarang tergolong tercemar ringan.

Perhitungan indeks keseragaman didapatkan hasil indeks keseragaman (E) fitoplankton di Pantai Maron Semarang yaitu 0,94-0,96. Menurut Nurcahyani et al. (2016), nilai indeks keseragaman tersebut tergolong dalam indeks keseragaman yang tinggi. Nilai rata-rata indeks keseragaman tertinggi berada di stasiun 2 yaitu 0,96 sedangkan nilai rata-rata indeks keseragaman terendah berada di stasiun 1 yaitu 0,94. Pada stasiun 3 memiliki rata-rata indeks keseragaman 0,95. Perbandingan indeks keseragaman (E) pada setiap stasiun di Pantai Maron Semarang tersaji pada Gambar 5.

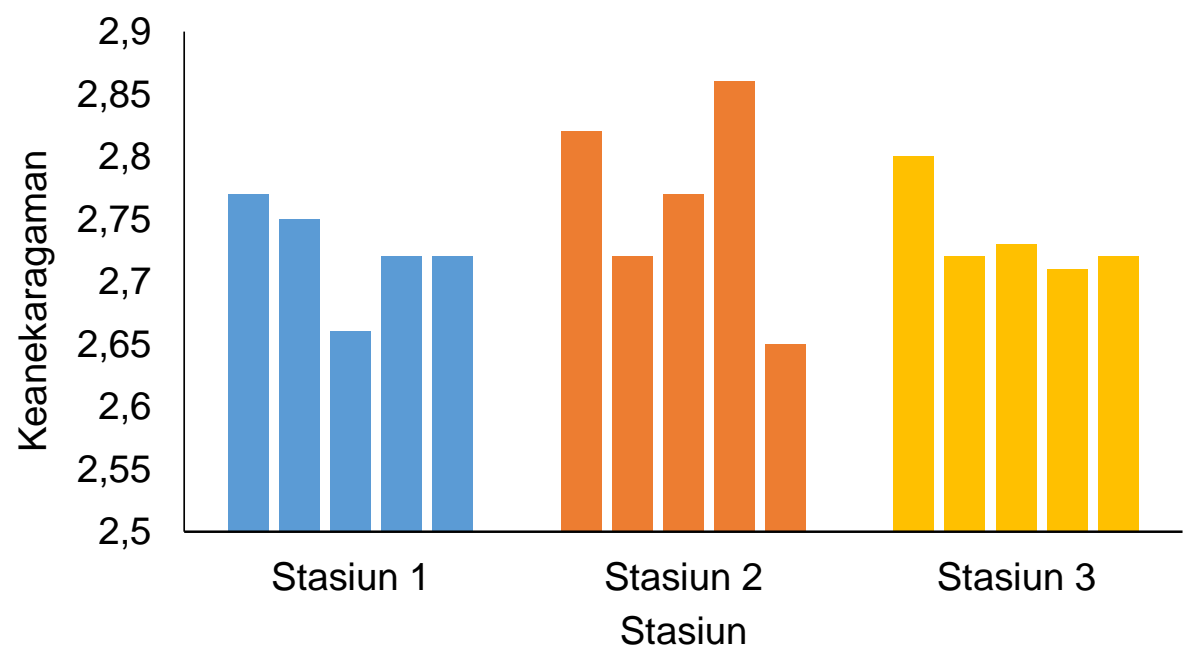

Gambar 4. Indeks Keanekaragaman Fitoplankton di Pantai Maron Semarang

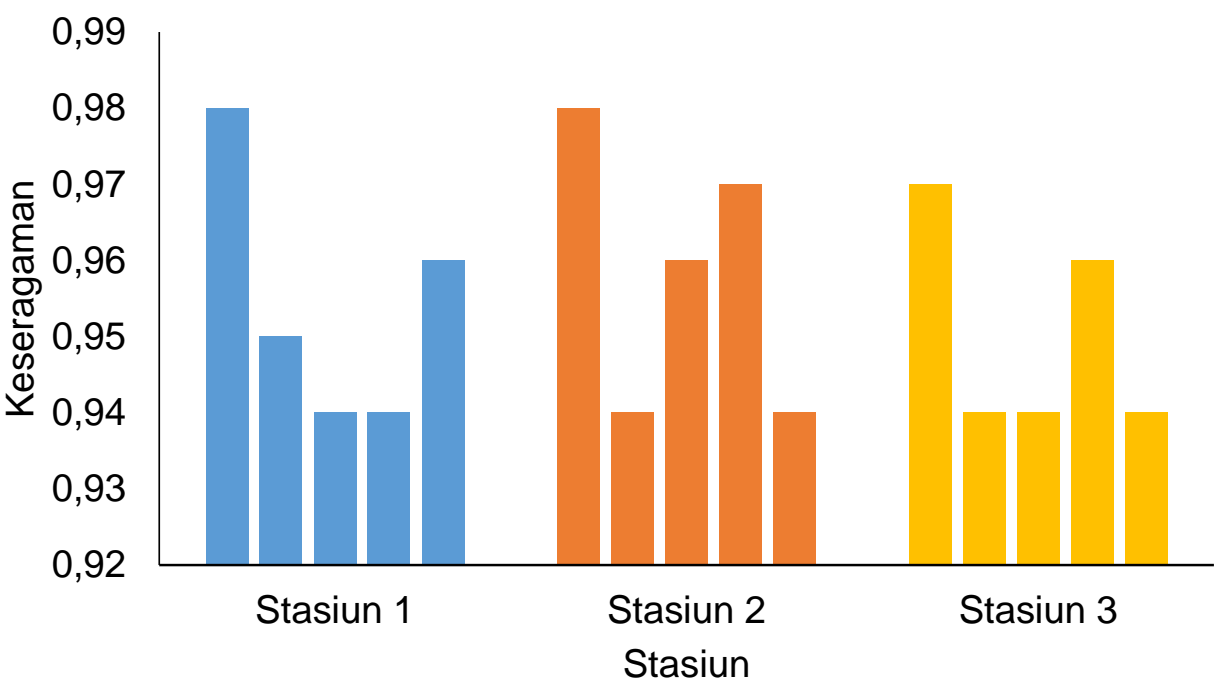

Gambar 5. Indeks Keseragaman Fitoplankton di Pantai Maron Semarang 


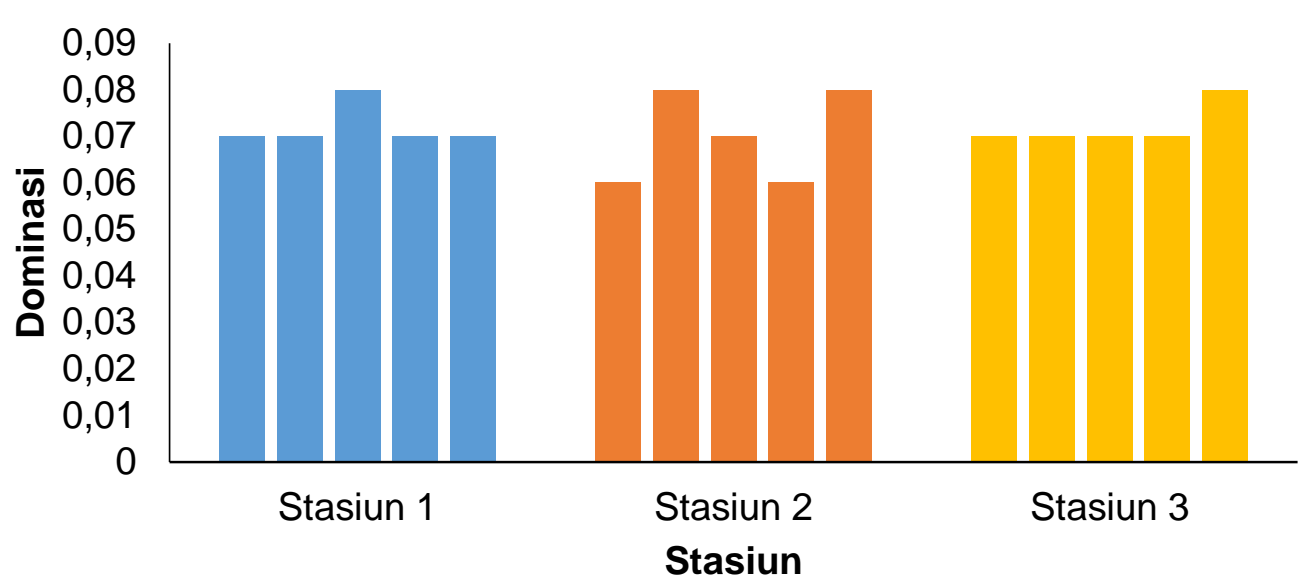

Gambar 6. Indeks Dominasi di Pantai Maron Semarang

Penyebaran jumlah individu pada masing-masing organisme dapat ditentukan dengan membandingkan nilai indeks keseragaman. Nilai dari indeks keseragaman fitoplankton ini menunjukkan kemampuan toleransi dari setiap jenis terhadap kualitas lingkungan. Individu yang memiliki kemampuan toleransi cukup tinggi yang sering ditemukan yaitu Rhizosolenia, Cerataulina, Pleurosigma, Nitzchia, Diatoma, Thalasiossira dan Prorocentrum. Perbedaan indeks keseragaman pada setiap stasiun dipengaruhi oleh jumlah individu jenis atau spesies dan jumlah individu seluruh jenis (jumlah total individu) yang ditemukan.

Indeks Dominasi di setiap stasiun bernilai 0,07 yang tergolong dominasi rendah atau tidak ada jenis yang mendominasi. Hal ini sesuai dengan pernyataan Sirait et al. (2017), menyatakan bahwa nilai indeks dominasi (D) yang mendekati 1 menunjukkan adanya dominasi yang tinggi dan sebaliknya nilai indeks yang mendekati 0 menunjukkan dominansi yang rendah atau tidak ada jenis yang mendominasi (Gambar 6). Parameter fisika-kimia air berada pada kisaran yang sesuai sehingga tidak terjadi kompetisi, semua genus memiliki peluang yang sama untuk dapat hidup dan berkembang biak. Parameter fisika-kimia air berada pada kisaran yang sesuai sehingga tidak terjadi kompetisi, semua genus memiliki peluang yang sama untuk dapat hidup dan berkembang biak. Hal ini sesuai dengan pernyataan Abida (2010), bahwa faktor-faktor lingkungan yang mempengaruhi dominansi suatu spesies adalah cahaya, temperatur, faktor perairan dan unsur hara yang digunakan untuk pertumbuhan fitoplankton.

\section{KESIMPULAN}

Hasil identifikasi fitoplankton ditemukan 3 kelas yaitu Bacillariophyceae, Dinophyceae dan Cyanophyceae yang terdiri dari 24 genera. Fitoplankton terbanyak yang ditemukan adalah kelas Bacillariophyceae yaitu 17 genus, selanjutnya kelas Dinophyceae ditemukan 6 genus, sedangkan kelas Cyanophyceae adalah kelas yang paling jarang ditemukan yaitu hanya 1 genus. Kelimpahan fitoplankton di Pantai Maron Semarang berkisar antara 7109,30-11549,89 sel/L. Indeks kenekaragaman tergolong sedang, indeks keseragaman tergolong tinggi dan indeks dominasi tergolong rendah.

\section{UCAPAN TERIMAKASIH}

Artikel ini adalah bagian dari skripsi dengan judul "Kelimpahan dan Distribusi Fitoplankton di Pantai Maron Semarang", untuk memperoleh gelar sarjana strata satu pada Departemen IImu Kelautan Fakultas Perikanan dan IImu Kelautan Universitas Diponegooro.

\section{DAFTAR PUSTAKA}

Abida, I.W. 2010. Struktur Komunitas dan Kelimpahan Fitoplankton di Perairan Muara Sungai Porong Sidoarjo. Jurnal Kelautan: Indonesian Journal of Marine Science and Technology, 
$3(1): 36-40$

Aprilia, A. 2015. Perilaku Ibu dalam Memberikan Pendidikan Seks Usia Dini pada Anak Pra Sekolah (Studi Deskriptif Eksploratif di TK IT Bina Insani Kota Semarang). Jurnal Kesehatan Masyarakat, 3(1):619-628.

Faturohman, I., Sunarto \& Nurruhwati, I. 2016. Korelasi Kelimpahan Plankton Dengan Suhu Perairan Laut di Sekitar PLTU Cirebon. Jurnal Perikanan Kelautan, 7(1):115-112.

Fithor, A., Indarjo A. \& Ario, R. 2013. Studi Kesesuaian Wisata dan Mutu Air Laut untuk Ekowisata Rekreasi Pantai di Pantai Maron Kota Semarang. Journal of Marine Research, 2(4):31-35. DOI: $10.14710 / j m r . v 2 i 4.3681$

Harmoko \& Sepriyaningsih. 2018. Keanekaragaman Mikroalga Chlorophyta di Sungai Kelingi Kota Lubuklinggau Sumatera Selatan. Jurnal Pro-life, 5(3):666-676.

Hidayat, D., Elvyra, R. \& Fatmawati. 2015. Keanekaragaman Plankton di Danau Simbad Desa Pulau Birandang Kecamatan Kampar Timur Kabupaten Kampar Provinsi Riau. Jom FMIPA, 2(1):115-129

Irawati, N., Adiwilaga, E.M. \& Prawtiwi, N.T.M. 2013. Hubungan Produktivitas Primer Fitoplankton dengan Ketersediaan Unsur Hara dan Intensitas Cahaya di Perairan Teluk Kendari Sulawesi Tenggara. Jurnal Biologi Tropis, 13(2):197-208.

Mujib, A.S., Dammar, A. \& Wardianto, Y. 2015. Distribusi Spasial Dinoflagellata Plantonik di Perairan Makassar, Sulawesi Selatan. Jurnal IImu dan Teknologi Kelautan Tropis, 7(2):479492. DOI: $10.29244 /$ jitkt.v7i2.11033

Munthe, Y.V., Aryawati, R. \& Isnani. 2012. Struktur Komunitas dan Sebaran Fitoplankton di Perairan Sungsang Sumatera Selatan. Maspari Journal, 4(1):122-130.

Nurcahyani E., Hutabarat, S. \& Sulardiono,B. 2016. Distribusi dan Kelimpahan Fitoplankton yang Berpotensi Menyebabkan HABs (Harmful Algal Blooms) di Muara Sungai Banjir Kanal Timur, Semarang. Diponegoro Journal of Maquares, 5(4): 275-284.

Nurlaelatun, H., Lalu, J. \& Santoso, D. 2018. Keanekaragaman dan Kelimpahan Diatom (Bacillariophyceae) di Pantai Jeranjang Desa Taman Ayu Kecamatan Gerung Kabupaten Lombok Barat. Jurnal Biologi Tropis, 18(1):13-20 DOI: 10.29303/jbt.v18i1.463.

Paiki, K., \& Kalor, J.D. 2017. Distribusi Nitrat dan Fosfat Terhadap Kelimpahan Fitoplankton di Perairan Pesisir Yapen Timur. Journal of Fisheries and Marine Science, 1(2):65-71

Patty, S. I. 2015. Karakteristik Fosfat, Nitrat dan Oksigen Terlarut di Perairan Selat Lembeh, Sulawesi Utara. Jurnal Pesisir dan Laut Tropis, 3(2):1-7. DOI: 10.24895/MIG.2018.20-2.645.

Patty, S. I. 2018. Oksigen Terlarut dan Apparent Oxygen Utilization di Perairan Selat Lembeh, Sulawesi Utara. Jurnal IImu Platax, 6(1). DOI: 10.35800/jip.6.1.2018.17972.

Simbolon, A. R. 2016. Pencemaran Bahan Organik dan Eutrofikasi di Perairan Cituis Pesisir Tangerang. Jurnal Pro-Life, 3(2):109-118

Sirait, M., F. Rahmatia dan Pattulloh. 2017. Komparasi Indeks Keanekaragaman dan Indeks Dominansi Fitoplankton di Sungai Ciliwung Jakarta. Jurnal Harpodon Borneo, 10(2):54-59 DOI: 10.35334/harpodon.v10i2.449

Widodo. 2014. Aplikasi Mikrofotografi Untuk Mengeksplorasi Jenis-Jenis Cyanophyta. Jurnal Florea, 1(2):8-13. DOI: 10.25273/florea.v1i2.382. 